\title{
Social inequalities in COVID-19 mortality by area and individual-level characteristics in Canada, January to July/August 2020: Results from two national data integrations
}

\author{
Alexandra Blair ${ }^{1 \star}$, Sai Yi Pan ${ }^{2}$, Rajendra Subedi ${ }^{3}$, Fei-Ju Yang ${ }^{3}$, Nicole Aitken ${ }^{3}$, Colin Steensma ${ }^{1}$
}

\begin{abstract}
Background: Despite early reports of social determinants of severe acute respiratory syndrome coronavirus 2 (SARS-CoV-2) infection and coronavirus disease 2019 (COVID-19) burden, national Canadian reporting on COVID-19 inequalities has been limited. The objective of this study is to describe inequalities in COVID-19 mortality in Canada using preliminary data, as part of the Pan-Canadian Health Inequalities Reporting Initiative.
\end{abstract}

Methods: Two provisional Canadian Vital Statistics Death Database integrations were used. Data concerning deaths between January 1 and July 4, 2020, among private-dwelling residents were linked to individual-level data from the 2016 short-form Census, and disaggregated by sex and low-income status, dwelling type, household type and size. Data concerning deaths between January 1 and August 31, 2020 linked to 2016 Census area data were disaggregated by sex and neighbourhood ethno-cultural composition quintiles (based on the proportion of residents who are recent immigrants, visible minorities, born outside of Canada, with no knowledge of English or French), income quintiles and urban residence. The COVID-19 age-standardized mortality rate (per 100,000 population) differences and ratios between groups were estimated.

Results: As of July/August 2020, apartment dwellers, residents of urban centres, neighbourhoods with the highest ethno-cultural composition or lowest income experienced 14 to 30 more COVID-19-related deaths/100,000 compared with reference groups (residents of single-detached homes, outside of urban centres, with lowest ethno-cultural concentration or highest income, respectively). Per 100,000 population, sex/gender inequalities were also larger in these four groups (11 to 18 more male than female deaths) than in the reference groups (two to four more male than female deaths).

Conclusion: These findings highlight how populations facing socioeconomic disadvantage have experienced a higher overall burden of deaths. Areas for future research are discussed to guide health equity-informed pandemic response.
This work is licensed under a Creative Commons Attribution 4.0 International License.

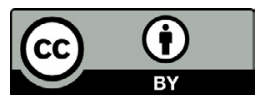

Affiliations

1 Social Determinants of Health Division, Public Health Agency of Canada, Montréal, QC

${ }^{2}$ Social Determinants of Health Division, Public Health Agency of Canada, Ottawa, ON

${ }^{3}$ Statistics Canada, Ottawa, ON

*Correspondence:

alexandra.blair@phac-aspc.gc.ca

Suggested citation: Blair A, Pan SY, Subedi R, Yang F-J, Aitken N, Steensma C. Social inequalities in COVID-19 mortality by area and individual-level characteristics in Canada, January to July/August 2020: Results from two national data integrations. Can Commun Dis Rep 2022;48(1):27-38. https://doi.org/10.14745/ccdr.v48i01a05

Keywords: SARS-CoV-2, COVID-19, mortality, social determinants of health, health equity, Canada

\section{Introduction}

Early regional $(1-3)$, provincial $(4,5)$ and national $(6,7)$ reporting in Canada has indicated that the burden of coronavirus disease 2019 (COVID-19) has not been experienced equally across all populations. Bivariate analyses suggest that racialized and lower-income populations have experienced higher rates of COVID-19 infection and mortality than white or higher-income groups, across several Canadian jurisdictions $(1,2,7)$. These studies highlight the importance of social and economic 
conditions known collectively as social determinants of health (8) in shaping the distribution of severe acute respiratory syndrome coronavirus 2 (SARS-CoV-2) infections and COVID-19 morbidity and mortality $(9,10)$.

Several hypotheses have been proposed to explain inequalities in COVID-19 mortality, each tied to underlying social determinants of health (9). First, they may be due to inequalities in SARS-CoV-2 infections due to systemic social and economic inequalities in living or working conditions $(9,11,12)$ in which prevention strategies, such as physical distancing or improved ventilation, are more difficult to apply or have not been implemented (13-15). Second, they may be attributable to long-standing (11) socioeconomic inequalities in the prevalence of underlying conditions and behaviours, such as smoking, obesity or diabetes, that place socioeconomically disadvantaged populations at higher risk of COVID-19 morbidity (16). Third, they may be attributable to underlying socioeconomic inequalities in healthcare access, use and quality $(9,11,17)$.

National-level reporting of COVID-19 mortality across socioeconomic groups in Canada remains limited (18) despite an expressed need from researchers and communities (19-21) to inform equitable pandemic preparedness and response. To fill this gap in national COVID-19 data reporting, this analysis sought to summarize individual and area-level absolute and relative inequalities in COVID-19 mortality that occurred between January and August 2020. This analysis is part of an ongoing effort of the Pan-Canadian Health Inequalities Reporting (HIR) Initiative (11).

\section{Methods}

\section{Data sources}

Data for this report come from two data integrations performed by Statistics Canada (for which the data integration team included co-authors RS, FJY, NA). Statistics Canada's data integration process refers to the combining two or more datasets. The data integrations described here were performed in the context of the COVID-19 pandemic to inform several studies, including the present one. One of the integrations performed was between the provisional Canadian Vital Statistics Death Database (CVSD) and the 2016 short-form Canadian Census of population (22). This individual-level record linkage was probabilistically linked to the Derived Record Depository in the Social Data Linkage Environment at Statistics Canada (23). The Social Data Linkage Environment is described as a "highly secure environment that facilitates the creation of linked population data files for social analysis. It is not a large integrated data base" (23). Among the provisional death records reported between January 1 and July 4, 2020, 96.4\% were probabilistically linked in the Derived Record Depository of the Social Data Linkage Environment. The linkage rate for the short-form census respondents to the Derived Record Depository was $96.8 \%$. This CSVD-Census linked data source includes COVID-19 deaths) that occurred between January 1 and July 4, 2020, for residents of private dwellings which represents $98 \%$ of the Canadian population ( $N=4,430$ deaths; 1,990 females, 2,440 males; all counts are rounded in accordance with Statistics Canada's disclosure rules $(6,22,24)$. Deaths that occurred in collective dwellings, including long-term care, were excluded.

The other data integration was between the provisional Canadian Vital Statistics Death Database and the area-level measures via the supplementary geographic information provided on the 2016 Census Postal Code Conversion File plus (PCCF+) (25). This CVSD-PCCF+ linked data source includes COVID-19 deaths that occurred between January 1 and August 31, 2020, regardless of dwelling status (rounded total of 9,265 COVID-19 deaths; 4,990 females, 4,275 males). Among the COVID-19 death records reported between January 1 and August 31, 2020, $99.7 \%$ had postal codes found in the PCCF+.

The Canadian Vital Statistics Death Database data are provisional and incomplete for several reasons. Namely, the dataset is sensitive to provincial and territorial reporting delays and it excludes deaths that occurred in the Yukon. However, COVID-19 mortality rates estimated using provisional Vital Statistics data are relatively similar (within 5\%) to those obtained using COVID-19 surveillance data (22). In addition, individuals' characteristics recorded in the 2016 Census may have changed by the time deaths were recorded in 2020. Nonetheless, these integrations are the best available sources of national Canadian data regarding the socioeconomic characteristics of COVID-19 deaths. They can provide early evidence about emerging public health issues to guide future research. They also provide baseline information upon which to base future monitoring.

\section{Measures}

The outcome studied was COVID-19 mortality, operationalized as cumulative age-standardized mortality rates per 100,000 population (hereafter referred to as "mortality rates per 100,000"; details on standardization are provided below). The Canadian Vital Statistics Death Database identifies COVID-19 deaths based on death certificates where COVID-19 is listed as the underlying cause of death. The ICD-10 codes U071 and U072 were used to identify, respectively, deaths among individuals who had received a positive SARS-CoV-2 test result (regardless of laboratory test used) and individuals identified as "possible" or "probable" cases, or who were "pending a (positive) test result."

Seven stratification measures were used to capture known social determinants of health, as identified in the Social Determinants of Health framework (8). From the integration of provisional Vital Statistics and short form 2016 Census data, four individual-level measures were used (i.e. based on the deceased's personal characteristics, recorded in the Census) to estimate disaggregated rates and inequalities. These measures were as follows: Statistics Canada's household after-tax low-income measure (26) (low-income versus not low-income 
[reference group]); dwelling type (i.e. apartment building fewer than five storeys, apartment building with five or more storeys, apartment in a duplex, row house, semi-detached house, versus single-detached house [reference group]) (6); household type (i.e. one-person, couple with children, couple without children, multigenerational household, two-or-more person non-census family household excluding multigenerational households, "other" census family household, versus lone-parent household [reference group]) (6); and household size (i.e. two, three, four, five-or-more person, versus one-person household [reference group]) (6).

From the integration of provisional Vital Statistics and PCCF+ data, three area level (27) measures were used (i.e. measures of the deceased's neighbourhood characteristics at the time of death, based on residential postal code information) to estimate disaggregated rates and inequalities. These measures were as follows: residence inside versus outside (reference group) of a Census Metropolitan Area (CMA) (i.e. large urban centre of 100,000 or more residents (28); after-tax national income per-person-equivalent quintiles (reference group: quintile 5, highest income); and quintiles of the national ethno-cultural composition dimension of the Canadian Index of Multiple Deprivation (reference group: quintile 1, lowest concentration). The latter is a composite indicator that captures the concentration of individuals who are recent immigrants (in the previous five years), designated as a visible minority, born outside of Canada or have no knowledge of either English or French. This type of measure can help capture populations that may be more vulnerable to systemic discrimination and disadvantage. For example, those who immigrate to Canada, particularly individuals identified as visible minorities, can experience structural or institutional forms of discrimination, particularly racial discrimination (i.e. "systemic" racism (29)), in areas such as labour and housing $(11,12)$.

Data were also disaggregated by sex. Though only data on sex (presumed at birth; "female" or "male") was available, this study hereafter refers to "sex/gender inequalities". As done in previous reporting (11), this usage is based on the assumption that the inequalities in COVID-19 mortality between males and females, like with other health conditions, are driven by determinants tied to both constructs of biological sex and gender (11).

\section{Analyses}

Rates overall and by sex were age-standardized using the direct method, based on the 2011 standard Canadian population, using age intervals of five years (30). Details on age groups, formulas and weights have been described previously (30). Rates were age-standardized to allow for comparison between groups that may have differences in age structure $(30,31)$. Confidence intervals for these rates were set at $95 \%$ and were calculated using the standard error of the standardized rate (details and formulas are provided in Supplemental Table S1) (32).
Age-standardized rates and confidence interval estimations were conducted using SAS 9.4 (33) and SAS Enterprise Guide 7.1 (34) software.

To assess relative and absolute inequalities in COVID-19 mortality, rate differences and ratios were estimated between subgroups, overall and by sex (according to principles of Sex and Gender Based Analysis Plus; SGBA+) by subtracting and dividing rates between subgroups, with $95 \%$ confidence intervals estimated using the standard error of the rates for each group in the comparison (formulas are provided in Supplement Table S1) $(35,36)$. Figures were created using $R$ software (version 4.0.2) (37). Since the inequality estimates were based on bivariate analyses, e-values (38) were estimated to assess the potential sensitivity of findings to unmeasured confounding. E-values capture the minimum size of an association between an unmeasured confounder and both the social stratification measures and the outcome of COVID-19 mortality risk to explain away an observed risk ratio. The e-value was estimated as follows: $R_{\text {observed }}+\sqrt{ }\left\{R R_{\text {observed }}\right.$ * $\left.\left(R_{\text {observed }}-1\right)\right\}$ (38). Higher e-values indicate that relatively strong confounding associations would be needed to completely explain away the observed exposure-outcome association (38).

\section{Results}

\section{Distribution of COVID-19 mortality across sub-populations}

At the start of the pandemic, between January 1 and July 4, 2020, COVID-19 mortality rates varied across the individual-level subgroups (Table 1). The lowest and the highest rates observed across the subgroups measured were among those living in two types of dwellings, respectively: rates ranged from nine deaths (for residents of single-detached homes) to 23 and 26 deaths (for residents of apartments) per 100,000. Rates were higher among males than females.

Between January 1 and August 31, 2020, COVID-19 mortality rates also varied according to area-level subgroups (Table 2). Per 100,000 , rates ranged from four deaths (for residents outside of large urban centres) to 33 to 37 deaths (for residents of large urban centres, areas with lowest income and highest ethnocultural concentration). Rates in these populations were again higher among males than females.

\section{Absolute and relative inequalities in COVID-19 mortality across subgroups}

Between January 1 and July 4, 2020, among the subgroups measured, the largest absolute inequalities in COVID-19 mortality among residents of private dwellings were observed between residents of apartments (in duplexes or multi-story 
Table 1: Age-standardized mortality rate per 100,000 population among residents of private dwellings, between January 1 and July 4, 2020, across individual-level stratifiers from the 2016 Census, overall and by sex

\begin{tabular}{|c|c|c|c|c|c|c|}
\hline \multirow{3}{*}{ Stratifiers } & \multicolumn{6}{|c|}{ Age-standardized mortality rate per 100,000 population } \\
\hline & \multicolumn{2}{|c|}{ Overall } & \multicolumn{2}{|c|}{ Females } & \multicolumn{2}{|c|}{ Males } \\
\hline & $\begin{array}{l}\text { Rate per } \\
100,000\end{array}$ & $95 \% \mathrm{Cl}$ & $\begin{array}{l}\text { Rate per } \\
100,000\end{array}$ & $95 \% \mathrm{Cl}$ & $\begin{array}{l}\text { Rate per } \\
100,000\end{array}$ & $95 \% \mathrm{Cl}$ \\
\hline \multicolumn{7}{|l|}{ Low-income measure status (after tax) } \\
\hline Not low-income & 14 & 13,14 & 11 & 10,11 & 18 & 17,19 \\
\hline Low-income & 19 & 18,20 & 15 & 14,17 & 27 & 25,30 \\
\hline \multicolumn{7}{|l|}{ Private dwelling type } \\
\hline Single-detached house & 9 & 9,10 & 7 & 7,8 & 11 & 11,12 \\
\hline Row house & 13 & 11,15 & 9 & 7,11 & 19 & 15,22 \\
\hline Semi-detached house & 16 & 13,18 & 12 & 9,15 & 20 & 16,24 \\
\hline Apartment in a building with five or more storeys & 23 & 21,24 & 18 & 16,19 & 33 & 30,35 \\
\hline Apartment in a building with fewer than five storeys & 24 & 23,26 & 18 & 16,20 & 36 & 33,39 \\
\hline Flat or apartment in a duplex & 26 & 23,29 & 19 & 16,21 & 37 & 32,42 \\
\hline \multicolumn{7}{|l|}{ Household type } \\
\hline Lone-parent family & 13 & 12,15 & 12 & 10,13 & 19 & 14,23 \\
\hline Multigenerational household & 14 & 13,16 & 13 & 11,15 & 17 & 14,20 \\
\hline One person household & 15 & 14,15 & 11 & 11,12 & 22 & 21,24 \\
\hline Other census family household ${ }^{\mathrm{a}}$ & 15 & 13,17 & 13 & 11,16 & 16 & 13,20 \\
\hline Couple without children & 16 & 16,17 & 14 & 12,15 & 18 & 17,19 \\
\hline Couple with children & 19 & 17,22 & 10 & 7,14 & 24 & 20,27 \\
\hline $\begin{array}{l}\text { Two or more person non-census family (excluding } \\
\text { multigenerational) }\end{array}$ & 23 & 20,27 & 19 & 15,23 & 32 & 25,39 \\
\hline \multicolumn{7}{|l|}{ Household size } \\
\hline 1 person & 15 & 14,15 & 11 & 11,12 & 22 & 21,24 \\
\hline 2 persons & 15 & 15,16 & 12 & 11,13 & 18 & 17,19 \\
\hline 3 persons & 15 & 14,17 & 11 & 9,12 & 21 & 18,24 \\
\hline 4 persons & 14 & 11,16 & 11 & 9,14 & 16 & 12,19 \\
\hline 5 persons or more & 17 & 15,19 & 15 & 12,17 & 20 & 16,23 \\
\hline
\end{tabular}

buildings) and those of detached homes. There were 14 to 17 more deaths per 100,000 (between 2.5 and 2.8 times higher rates) among apartment residents compared with single-detached home residents (Figure 1) (data presented in Figures 1 to 4 are available in Supplemental Tables S2 to S5, respectively). Smaller inequalities were observed between those living in other dwelling types (row and semi-detached houses) and those living in single-detached homes (observed rate ratios ranged from 1.4 to 1.7, rate differences of 4 to 6 more deaths per 100,000). Similarly, smaller inequalities were also observed across household type and low-income status subgroups; observed rate ratios ranged from 1.1 to 1.8 , and rate differences of one to 10 more deaths per 100,000 in these subgroups (Figure 1). There were small to no differences in rates across household sizes (as indicated by $95 \%$ confidence intervals that crossed the null) (Figure 1). Sensitivity e-value analyses were conducted to assess the potential risk of confounding bias on these bivariate inequality estimates. Findings suggest that the observed inequalities in COVID-19 mortality risk according to low-income status, household type and dwelling type could be fully explained away by an unmeasured confounder with an association of $R R=2.1$ to 5.0 (depending on the social strata), with both the latter exposure measures and the outcome of COVID-19 mortality, respectively (Supplemental Table S6). That is, the unmeasured confounder would have to have a stronger association than those observed for the factors measured in this study (Figure 1).

Between January 1 and August 31, 2020, among the subgroups measured, the largest absolute inequalities in COVID-19 mortality overall were observed between residents living within versus outside large urban centres. There were 30 
Table 2: Age-standardized mortality rate per 100,000 population among all residents, January 1 and August 31, 2020, across area-level stratifiers from the 2016 Census, overall and by sex

\begin{tabular}{|c|c|c|c|c|c|c|}
\hline \multirow{3}{*}{ Stratifiers } & \multicolumn{6}{|c|}{ Age-standardized mortality rate per 100,000 population } \\
\hline & \multicolumn{2}{|c|}{ Overall } & \multicolumn{2}{|c|}{ Females } & \multicolumn{2}{|c|}{ Males } \\
\hline & $\begin{array}{l}\text { Rate per } \\
100,000\end{array}$ & $95 \% \mathrm{Cl}$ & $\begin{array}{c}\text { Rate per } \\
100,000\end{array}$ & $95 \% \mathrm{Cl}$ & $\begin{array}{l}\text { Rate per } \\
100,000\end{array}$ & $95 \% \mathrm{Cl}$ \\
\hline \multicolumn{7}{|l|}{ Census metropolitan area (CMA) } \\
\hline Living in large urban centers (Census Metropolitan Area, CMA) & 33 & 32,34 & 29 & 28,29 & 39 & 38,41 \\
\hline Living outside large urban centers (non-CMA) & 4 & 3,4 & 3 & 2,3 & 5 & 4,5 \\
\hline \multicolumn{7}{|l|}{ Ethno-cultural composition } \\
\hline Quintile 1 (lowest concentration) & 16 & 15,17 & 14 & 13,15 & 18 & 17,20 \\
\hline Quintile 2 & 13 & 12,14 & 12 & 11,13 & 14 & 13,16 \\
\hline Quintile 3 & 19 & 18,20 & 16 & 15,17 & 22 & 20,24 \\
\hline Quintile 4 & 30 & 29,31 & 25 & 24,27 & 37 & 35,39 \\
\hline Quintile 5 & 37 & 35,38 & 31 & 30,33 & 44 & 42,47 \\
\hline \multicolumn{7}{|l|}{ After-tax neighbourhood income } \\
\hline Quintile 1 (lowest income) & 37 & 36,39 & 30 & 29,32 & 48 & 46,50 \\
\hline Quintile 2 & 20 & 19,20 & 16 & 15,17 & 24 & 22,25 \\
\hline Quintile 3 & 20 & 19,21 & 18 & 17,20 & 22 & 20,24 \\
\hline Quintile 4 & 18 & 17,19 & 16 & 15,17 & 21 & 20,23 \\
\hline Quintile 5 & 17 & 16,18 & 16 & 15,18 & 18 & 17,20 \\
\hline
\end{tabular}

Figure 1: Rate differences and ratios in age-standardized mortality rates (per 100,000) by individual-level characteristics, January 1 to July 4, 2020

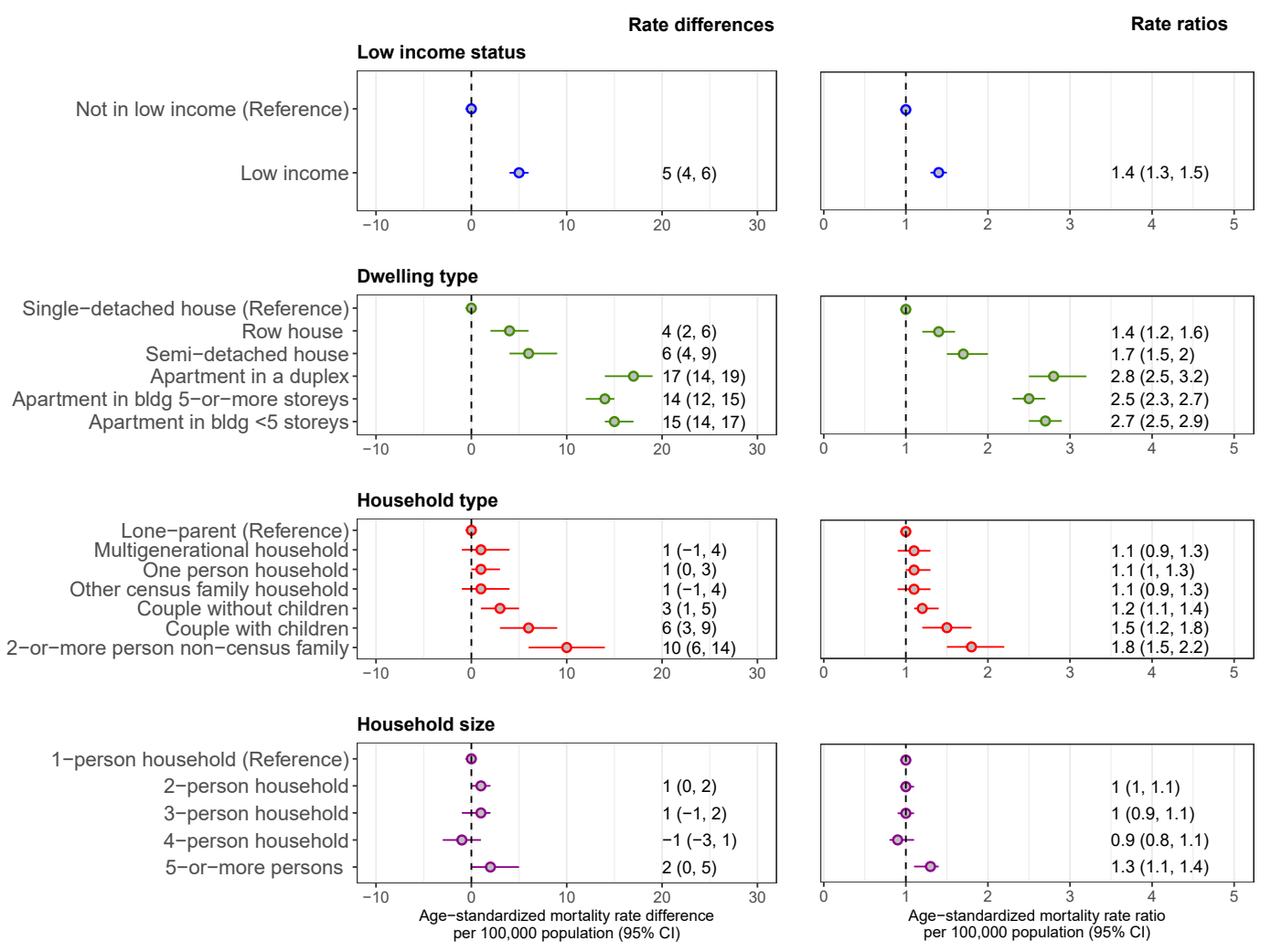


more deaths per 100,000 (9.5 times higher rates) within urban centres (Figure 2). Large inequalities were also observed across ethno-cultural and income quintiles. Per 100,000, there were 14 to 21 more deaths (1.9 to 2.3 times higher rates) in the highest ethno-cultural composition concentration areas (quintiles 4 and 5 versus quintile 1) and 20 more deaths (2.1 times higher rates) in lowest income areas (quintile 1 versus quintile 5) (Figure 2). Sensitivity analyses suggested that the latter observed associations could only be fully explained away by an unmeasured confounder with an association of $R R=3.2$ to 18.5 , depending on the social strata, with both the latter exposures and the outcome, respectively (Supplemental Table S7). Rate differences for the other neighbourhood income quintile groups (quintiles 2 to 4 ) and ethno-cultural quintile groups (quintiles 2 to 3 ), ranged from one to three deaths per 100,000 (ratios of 0.8 to 1.2 ), with many of the $95 \%$ confidence intervals crossing the null (Figure 2).

\section{Sex/gender inequalities in COVID-19 mortality across sub-populations}

Between January 1 and July 4, 2020, among residents of private dwellings, the largest inequalities in mortality between males and females were among apartment dwellers (difference of 15 to 18 more deaths per 100,000 , male-to-female ratios of 1.8 to 2) (Figure 3). Within other dwelling type subgroups, rate differences ranged from four to 10 deaths per 100,000 (male-to-female ratios of 1.6 to 2.1 ) (Figure 3).

Among household types, the largest sex/gender inequalities were within one-person households, two-or-more non-census family households and couples with children (rate differences of 11 to 13 per 100,000 , male-to-female ratios of 1.7 to 2.3 ) (Figure $3)$. In the other household types, differences ranged from three to seven per 100,000 (male-to-female ratios of 1.2 to 1.6 ), with several $95 \%$ confidence intervals crossing the null (Figure 3 ).

Figure 2: Rate differences and ratios in age-standardized mortality rates (per 100,000) by area-level characteristics, January 1 to August 31, 2020

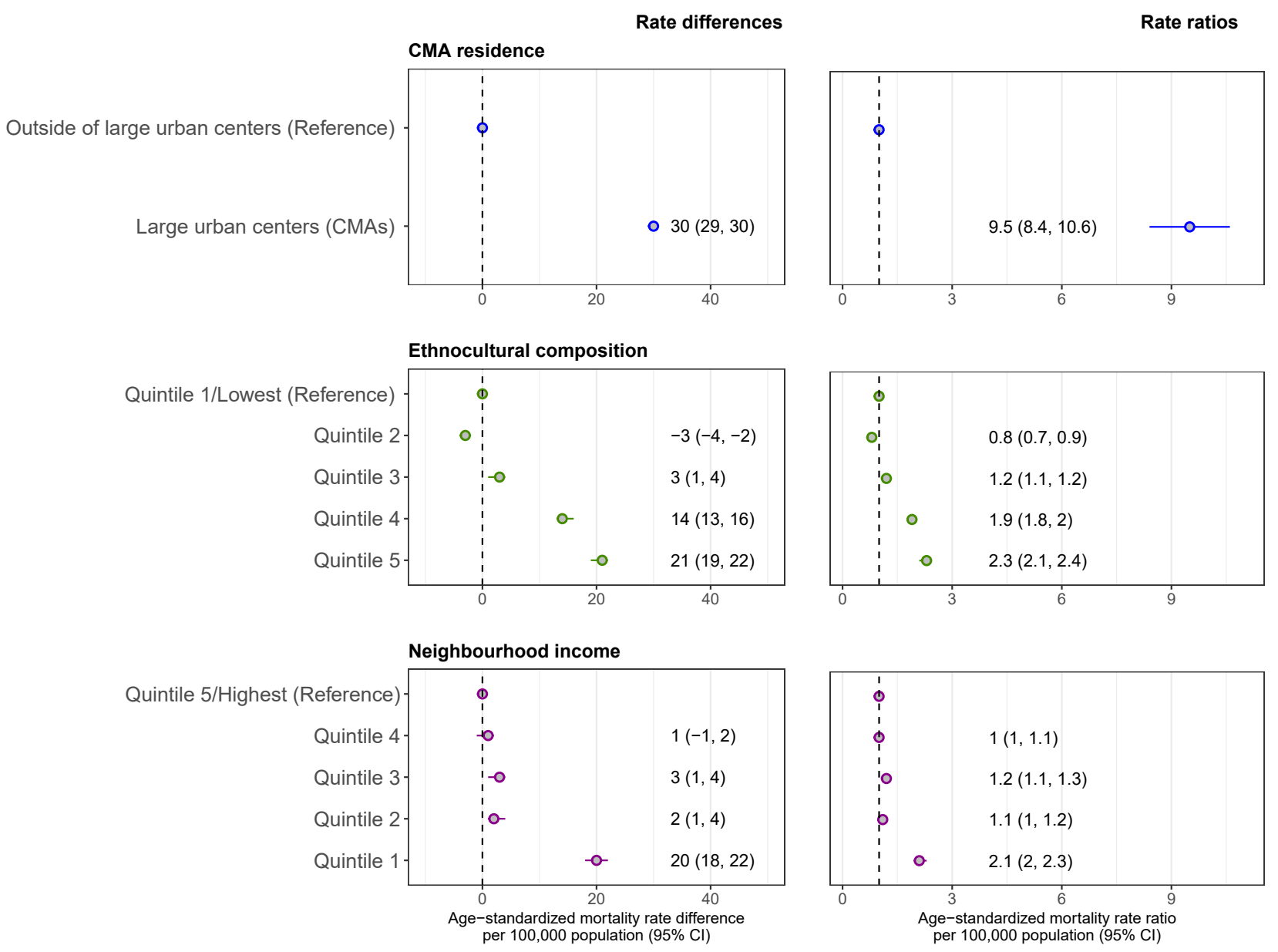

Abbreviation: CMA, Census Metropolitan Area 
Figure 3: Age-standardized mortality rate differences and ratios between males and females (reference group) by individual-level subgroups, January 1 to July 4, 2020

Male vs. female rate differences

Male vs. female rate ratios
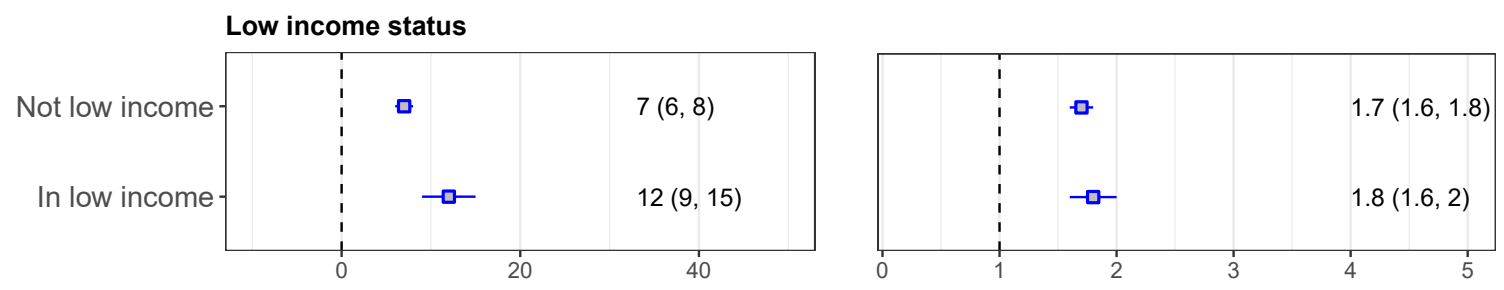

Dwelling type
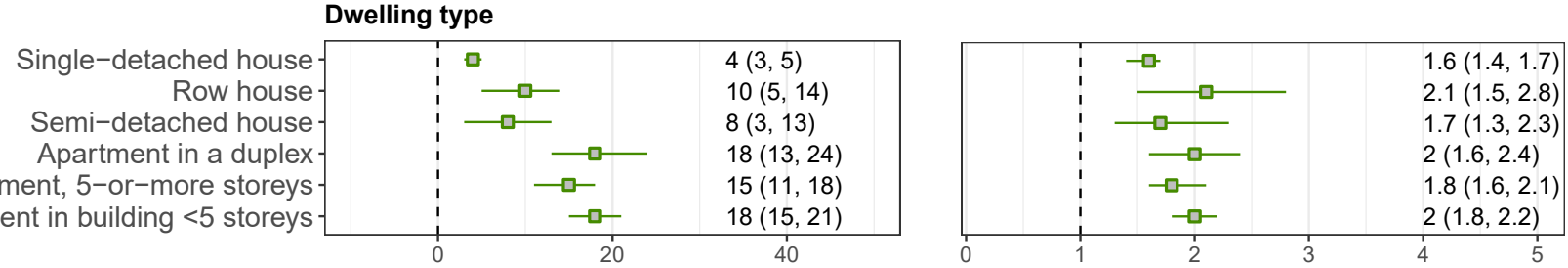

Apartment, 5-or-more storeys Apartment in building $<5$ storeys

\section{Household type}
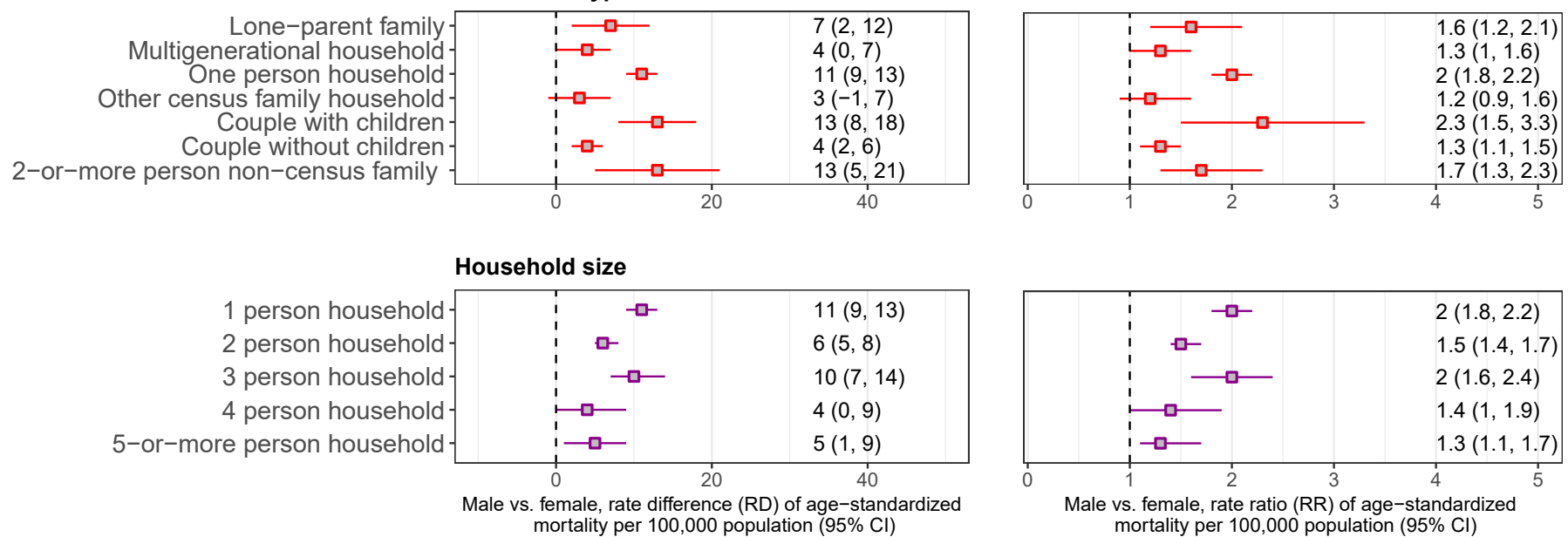

Males experienced 12 more deaths per 100,000 (male-to-female ratio of 1.8) in low-income groups, compared with seven more deaths per 100,000 (male-to-female ratio of 1.7) in groups not in low-income (Figure 3). Lastly, compared with females, males experienced between six and 11 more deaths in one to three-person households (1.5 to 2 times higher rates) (Figure 3 ). In the other household size subgroups, the $95 \%$ confidence intervals for the rate differences and ratios were close to the null (Figure 3).
Similarly, between January 1 and August 31, 2020, sex/gender inequalities varied across area-level disaggregates. There were 11 more male than female deaths per 100,000 in CMAs compared with two more male deaths per 100,000 outside of urban centres (Figure 4). The difference in mortality rates between males and females was highest in areas with lowest income or highest ethno-cultural composition concentration: per 100,000, there were 18 more male deaths in income quintile 1 (1.6 times higher rates) and 13 more male deaths in ethno-cultural composition quintile 5 (1.4 times higher rates) (Figure 4). 
Figure 4: Age-standardized mortality rate differences and ratios between males and females (reference group) by area-level subgroups, January 1 to August 31, 2020

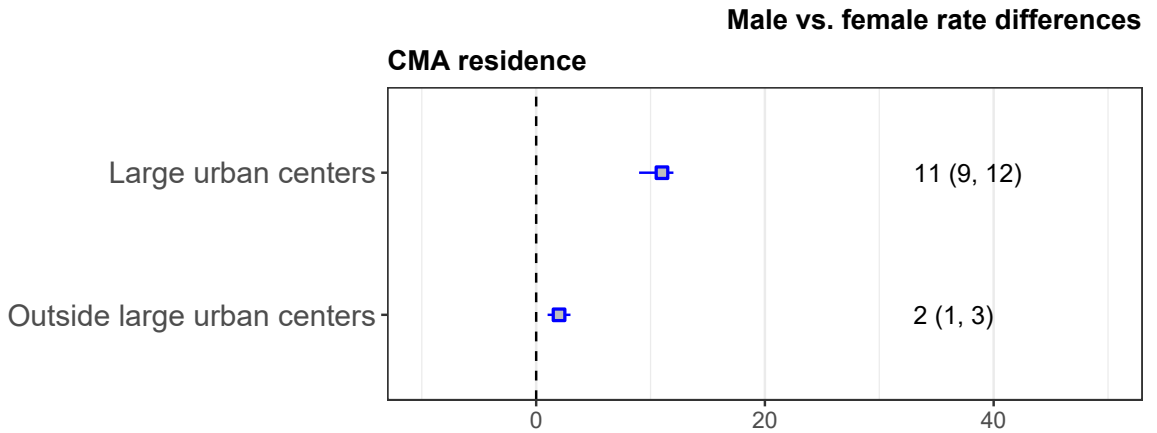

Male vs. female rate ratios
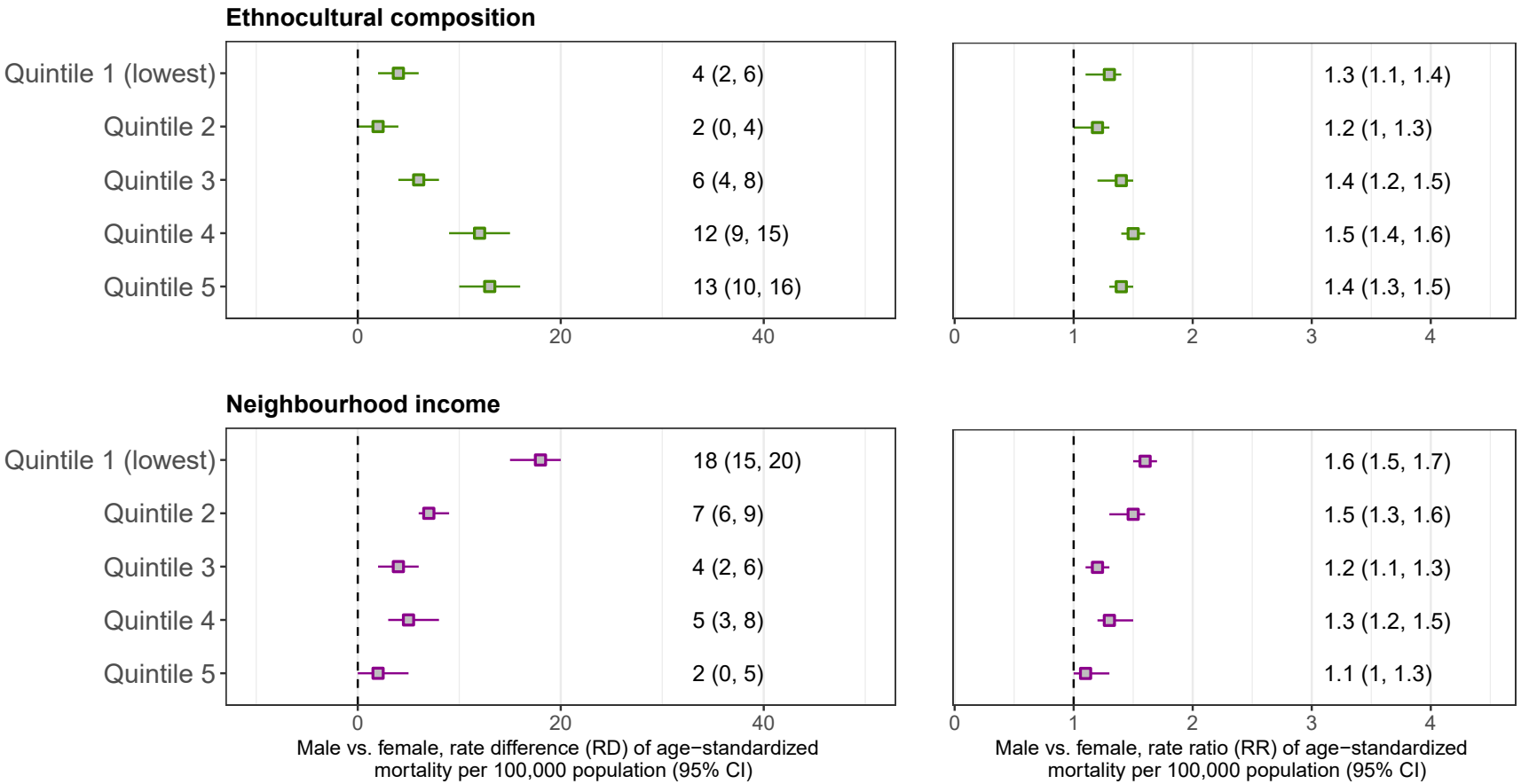

Abbreviation: CMA, Census Metropolitan Area

\section{Discussion}

This study aimed to provide a snapshot of the individual and area-level inequalities in COVID-19 mortality in Canada at the start of the pandemic. At an individual-level, the largest inequalities in mortality were observed between apartment residents and single-detached house residents. At an area-level, large inequalities were observed between those living in large urban centres, in lowest income and highest ethno-cultural composition concentration areas, compared with respective reference groups. Inequalities in male versus female mortality rates were also higher in each of the above subgroups. These findings highlight how populations facing socioeconomic disadvantage have experienced a higher overall burden of deaths.
The observed inequalities, particularly in relation to income and ethno-cultural composition, are consistent with previous Canadian findings at regional $(1-3)$, provincial $(4,5)$ and national $(6,7,39)$ levels. Further, inequalities by sex/gender and area-level income are also aligned with what has been observed for other infectious and chronic disease outcomes and overall mortality in Canada $(11,40,41)$.

Previous reporting has highlighted that inequalities in COVID-19 mortality are likely attributable to social and economic differences in SARS-CoV-2 infection (13-15), and distributions of underlying mortality risk factors, including chronic condition prevalence and access to and use of health services (9). For example, systemic inequities in working and living conditions can shape inequitable distributions of infections and morbidity risk (8). The larger sex/gender inequalities in COVID-19 mortality observed in some subgroups are likely an indication of the 
interplay between sex-based immunological factors (42) and gendered domestic and occupational experiences that shape infection and morbidity risk, including risk behaviours (e.g. smoking, lower use of health care services (11)) and chronic disease prevalence (42).

Further, included in hypothesized social determinants of COVID-19 outcomes are public health measures, which can have differential impacts across populations, especially with regards to SARS-CoV-2 transmission. For example, a Toronto Foundation report indicated how closures of nonessential workplaces were associated with lower SARS-CoV-2 transmission rates in higher-income neighbourhoods, where more residents could work from home (43). This policy appeared to be less effective in areas with lower income and higher concentration of visible minority populations (43). It is common for universal public health strategies to have differential impacts if certain socioeconomic groups face structural barriers in experiencing the benefits of interventions $(44,45)$, such as inability to work from home (46), absence of discretionary time or linguistic differences (11). Strategies that combine universal and targeted approaches, based on the proportionate needs of populations, are believed to be able to overcome these limitations (47).

Perhaps most importantly, the burden of COVID-19 observed in some groups but not others highlights how inequalities in COVID-19 mortality could plausibly be avoided and therefore considered inequitable (48). In light of these findings, it is evident that work needs to be done in Canada to advance health equity during this pandemic and into the future so that these inequities can be prevented, as proposed in the Key Health Inequalities in Canada report (11).

\section{Limitations}

This study has several limitations. First, this analysis is intended to better understand differences in mortality between populations, using the best available sources of data. However, as noted, the provisional data used herein likely underestimated COVID-19 mortality rates. The rates reported do not capture all COVID-19 deaths that occurred in Canada in the study period. It is unclear how under-reporting may have influenced the magnitude of inequalities observed. It is also not yet known how differences in under-reporting across groups, or spatialtemporal changes in under-reporting or transmission rates, may have influenced the size of inequalities across time. Second, due to limitations in data access, this study did not explore interactions between measures, nor was a multivariate analysis performed to identify the precise pathways through which these inequalities manifest. Although sensitivity analyses performed suggested moderate to minimal vulnerability to confounding bias for observed associations, future multivariate analyses are needed to address these data gaps. Third, individuals' personal or area-level characteristics may have changed between the time of the 2016 Census collection and when the deaths occurred. It is unclear how this may have influenced inequality estimates. It was not possible in this study to distinguish which of the deaths integrated with area-level data, or inequalities therein, occurred among residents of long-term care institutions and which occurred in private dwellings. These remain important areas of future study. Lastly, this study did not explore several other social determinants, including gender, Indigeneity or race/ethnicity, as these data were not available. An exploration of these social determinants, and of inequalities by province and territory, at later time points during the pandemic, including following the advent of variants of concern (49) and immunization campaigns, remain other important areas of future investigation.

\section{Conclusion}

The burden of COVID-19 mortality between January and July/ August 2020 was not experienced equally across all populations and communities in Canada. This study highlights the role of social determinants of health and socioeconomic inequalities in shaping inequitable distributions of COVID-19 burden, and the need to consider these factors in future analyses, to prepare a health equity-informed pandemic response.

\section{Authors' statement}

$A B$ - Conceptualized the study, performed analyses of absolute and relative inequalities, interpreted the data, drafted the manuscript, and revised the manuscript

SYP - Conceptualized the study, performed analyses of absolute and relative inequalities, drafted and provided feedback on the manuscript

NA - Estimated disaggregated rates and provided feedback on the manuscript

FJY - Estimated disaggregated rates and provided feedback on the manuscript

RS - Estimated disaggregated rates and provided feedback on the manuscript

CS - Conceptualized the study and provided feedback on the manuscript

\section{Competing interests}

None.

\section{Acknowledgements}

This analysis is a product of the Pan-Canadian Health Inequalities Reporting (HIR) Initiative. Established in 2012 and led by the Public Health Agency of Canada (PHAC), the HIR Initiative involves a collaboration between PHAC, Statistics Canada, the Pan-Canadian Public Health Network, the Canadian Institute for Health Information and the First Nations Information Governance Centre. Past HIR Initiative reporting has included an online health inequality data visualization tool (the Health Inequalities Data 
Tool) and the 2018 Key Health Inequalities in Canada: A National Portrait. We would like to acknowledge the contributions of Scott Van Millingen and Hongbo Liang on the development of the HIR Initiative COVID-19 Data Tool and the Health Inequalities Data Tool.

\section{Funding}

This work was supported by the Public Health Agency of Canada.

\section{Supplemental material}

These documents can be accessed on the Supplemental tables file.

Supplemental Table S1

Supplemental Table S2

Supplemental Table S3

Supplemental Table S4

Supplemental Table S5

Supplemental Table S6

Supplemental Table S7

\section{References}

1. Toronto Public Health. COVID-19: Pandemic Data. Toronto (ON): TPH; June 2021 (accessed 2021-10-27). https://www. toronto.ca/home/covid-19/covid-19-pandemic-data/

2. Ottawa Public Health. COVID-19 and Racial Identity in Ottawa; February to August 2020. Toronto (ON): TPH; November 2020 (accessed 2021-10-27). https://www. ottawapublichealth.ca/en/reports-research-and-statistics/ resources/Documents/covid-19/Special-Focus/Report--COVID-19-and-Racial-Identity-in-Ottawa-2020.pdf

3. Direction régionale de la santé publique de Montréal. Survey of the health of Montrealers during the pandemic. Montréal (QC) : Santé Montréal; 2020 (accessed 2021-10-27).

https://santemontreal.qc.ca/en/public/coronavirus-covid-19/ situation-of-the-coronavirus-covid-19-in-montreal/survey-ofthe-health/racialized-populations/\#c44846

4. ICES. ICES releases report on COVID-19 in immigrants, refugees and other newcomers in Ontario. ICES; September 2020 (accessed 2021-10-27). https://www.ices. on.ca/Newsroom/Announcements-and-Events/2020/ICESreleases-report-on-COVID-19-in-Immigrants-Refugees-andOther-Newcomers-in-Ontario

5. Chung H, Fung K, Ferreira-Legere LE, Chen B, Ishiguro L, Kalappa G, Gozdyra P, Campbell T, Paterson JM, Bronskill SE, Kwong JC, Guttmann A, Azimaee M, Vermeulen MJ, Schull MJ. COVID-19 Laboratory Testing in Ontario: Patterns of Testing and Characteristics of Individuals Tested, as of April 30; 2020. ICES, 2020 (accessed 2021-10-27). https://www.ices.on.ca/Publications/Atlasesand-Reports/2020/COVID-19-Laboratory-Testing-in-Ontario
6. Statistics Canada. Yang F, Aitken N. People living in apartments and larger households were at higher risk of dying from COVID-19 during the first wave of the pandemic. Ottawa (ON): StatCan; 2021 (accessed 2021-10-27). https://www150.statcan.gc.ca/n1/pub/45-28-0001/2021001/ article/00004-eng.htm

7. Statistics Canada. StatCan COVID-19: Data to Insights for a Better Canada. Subedi R, Greenberg L, Turcotte M. COVID-19 mortality rates in Canada's ethno-cultural neighbourhoods. Ottawa (ON): StatCan; 2020 (accessed 2021-10-27). https://www150.statcan.gc.ca/n1/pub/45-280001/2020001/article/00079-eng.htm

8. World Health Organization. Solar O, Irwin A. A conceptual framework for action on the social determinants of health. Geneva, CH; WHO; 2010 (accessed 2021-10-27). https:// www.who.int/sdhconference/resources/Conceptualframewor kforactiononSDH_eng.pdf

9. Public Health Agency of Canada. From risk to resilience: An equity approach to COVID-19. Chief Public Health Officer Report. Ottawa (ON): PHAC; 2020 (accessed 2021-10-27). https://www.canada.ca/en/public-health/corporate/ publications/chief-public-health-officer-reports-state-publichealth-canada/from-risk-resilience-equity-approach-covid-19. html\#a2.2

10. Mishra S, Kwong JC, Chan AK, Baral SD. Understanding heterogeneity to inform the public health response to COVID-19 in Canada. CMAJ 2020;192(25):E684-5. DOl PubMed

11. Public Health Agency of Canada. Key Health Inequalities in Canada: A National Portrait. Ottawa (ON): PHAC; 2018 (accessed 2021-10-27). https://www.canada.ca/en/ public-health/services/publications/science-research-data/ key-health-inequalities-canada-national-portrait-executivesummary.html

12. Walk RA, Bourne LS. Ghettos in Canada's cities? Racial segregation, ethnic enclaves and poverty concentration in Canadian urban areas. Can Geogr 2006;50(3):273-97. DOI

13. Bi Q, Wu Y, Mei S, Ye C, Zou X, Zhang Z, Liu X, Wei L, Truelove SA, Zhang T, Gao W, Cheng C, Tang X, Wu X, Wu Y, Sun B, Huang S, Sun Y, Zhang J, Ma T, Lessler J, Feng T. Epidemiology and transmission of COVID-19 in 391 cases and 1286 of their close contacts in Shenzhen, China: a retrospective cohort study. Lancet Infect Dis 2020;20(8):911-9. DOl PubMed

14. International Long Term Care Policy Network. Hsu AT, Lane N, Sinha SK, Dunning J, Dhuper M, Kahiel Z, Sveistrup H. Impact of COVID-19 on residents of Canada's long-term care homes-ongoing challenges and policy responses. ILTCPN; 2020 (accessed 2021-10-27). https://ltccovid.org/wp-content/uploads/2020/05/LTCcovidcountry-reports_Canada_Hsu-et-al_May-10-2020-2.pdf

15. Leso V, Fontana L, lavicoli I. Susceptibility to Coronavirus (COVID-19) in Occupational Settings: The Complex Interplay between Individual and Workplace Factors. Int J Environ Res Public Health 2021;18(3):10. DOI PubMed 
16. Statistics Canada. StatCan COVID-19: Data to Insights for a Better Canada. O'Brien K, St-Jean M, Wood P, Willbond S, Phillips O, Currie D, Turcotte M. COVID-19 death comorbidities in Canada. Ottawa (ON): StatCan; 2020 (accessed 2021-10-27). https://www150.statcan.gc.ca/n1/ pub/45-28-0001/2020001/article/00087-eng.htm

17. Bryant T, Leaver C, Dunn J. Unmet healthcare need, gender, and health inequalities in Canada. Health Policy 2009;91(1):24-32. DOl PubMed

18. Blair A, Warsame K, Naik H, Byrne W, Parnia A, Siddiqi A. Identifying gaps in COVID-19 health equity data reporting in Canada using a scorecard approach. Can J Public Health 2021;112(3):352-62. DOl PubMed

19. Center for Research-Action on Race Relations. CRARR Calls on Federal and Quebec Governments to Collect COVID-19 Data Based on Race, Language, Income Level. Montreal (QC): CRARR; 2020 (accessed 2021-10-27). http://www.crarr. org/?q=node/20102

20. Béland F. Pandémie, iniquités, santé publique, information, interventions : I'échec canadien? Can J Public Health 2021;112(3):349-51. DOl PubMed

21. McKenzie K. Socio-demographic data collection and equity in covid-19 in Toronto. EClinicalMedicine 2021;34(100812):100812. DOl PubMed

22. Statistics Canada. Provisional death counts and excess mortality, January to August 2020. Ottawa (ON): StatCan; 2020 (accessed 2021-11-03). https://www150.statcan.gc.ca/ n1/daily-quotidien/201028/dq201028b-eng.htm

23. Statistics Canada. Social Data Linkage Environment: Overview. Ottawa (ON): StatCan; 2017 (accessed 2021-11-03). https://www.statcan.gc.ca/en/sdle/overview

24. Statistics Canada. Data tables, 2016 Census. Census Population, Dwellings and Households of Canada, Provinces and Territories, 1981 to 2016. Catalogue no. 98-400-X2016013. Ottawa (ON): StatCan; 2016 (accessed 2021-11-03). https://www12.statcan.gc.ca/censusrecensement/2016/dp-pd/dt-td/Rp-eng.cfm?TABID=2\&La $\mathrm{ng}=\mathrm{E} \& A P A T H=3 \& D E T A I L=0 \& D I M=0 \& F L=A \& F R E E=0 \& G$ $C=0 \& G I D=1234492 \& G K=0 \& G R P=1 \& P I D=109532 \& P R I D=$ 10\&PTYPE $=109445 \& S=0 \& S H O W A L L=0 \& S U B=0 \& T e m p o r$ $\mathrm{al}=2016 \& \mathrm{THEME}=116 \& \mathrm{VID}=0 \& \mathrm{VNAMEE}=\& \mathrm{VNAMEF}=\& \mathrm{D} 1=$ $0 \& D 2=0 \& D 3=0 \& D 4=0 \& D 5=0 \& D 6=0$

25. Statistics Canada. Postal CodeOM Conversion File Plus (PCCF+). Ottawa (ON): StatCan; 2021 (accessed 2021-10-27). https://www150.statcan.gc.ca/n1/en/ catalogue/82F0086X

26. Statistics Canada. Income Research Paper Series. Low Income Lines: What they are and how they are created. Ottawa (ON): StatCan; 2016 (accessed 2021-10-27). https://www150.statcan.gc.ca/n1/ pub/75f0002m/75f0002m2016002-eng.htm
27. Statistics Canada. Dictionary, Census of Population, 2016: Dissemination Area (DA). Ottawa (ON): StatCan; 2016 (accessed 2021-05-17). https://www12.statcan.gc.ca/censusrecensement/2016/ref/dict/geo021-eng.cfm

28. Statistics Canada. CMA and CA: Detailed definition. Ottawa (ON): StatCan; 2018 (accessed 2021-05-17). https://www150 statcan.gc.ca/n1/pub/92-195-x/2011001/geo/cma-rmr/defeng.htm

29. National Collaborating Centre for Determinants of Health. Let's talk racism and health equity. Antigonish (NS): $\mathrm{NCCDH}$; 2020 (accessed 2021-10-27). https://nccdh.ca/resources/ entry/lets-talk-racism-and-health-equity

30. Statistics Canada. Vital Statistics Death Database - Glossary. Ottawa (ON): StatCan; 2017 (accessed 2021-11-03). https://www.statcan.gc.ca/en/statistical-programs/ document/3233_D4_T9_V1

31. Statistics Canada. Behind the Data: Age-standardized Rates. Ottawa (ON): StatCan; 2017 (accessed 2021-10-27). https://www.statcan.gc.ca/en/dai/btd/asr

32. Statistics Canada. Data quality, concepts and methodology: Health status indicators based on vital statistics. Ottawa (ON): StatCan; 2016 (accessed 2021-11-03). https://www150. statcan.gc.ca/n1/pub/82-221-x/2013001/quality-qualite/ qual-eng.htm

33. SAS Institute. Base SAS 9.4 Procedures Guide (5 $5^{\text {th }}$ edition). SAS Institute Inc., USA; 2015. https://support.sas.com/ content/dam/SAS/support/en/documentation/third-partyreference/493971_9.4-indbag-5th-ed.pdf

34. SAS Institute. Statistics using SAS Enterprise Guide. Cambridge University Press, UK; 2009. DOI

35. Harvard School of Public Health. The Public Health Disparities Geocoding Project. The Public Health Disparities Geocoding Project Monograph: Analytic Methods. Boston (MA): HSPH; 2021 (accessed 2021-06-15). https://www.hsph. harvard.edu/thegeocodingproject/analytic-methods/

36. Rothman K, Greenland S. Modern Epidemiology. $2^{\text {nd }}$ ed. Philadelphia (PA): Lippincott William and Wilkins; 1998. https://www.rti.org/publication/modern-epidemiology-2ndedition

37. The R Project for Statistical Computing. R version 4.0.2; 2020. https://www.r-project.org/

38. VanderWeele TJ, Ding P. Sensitivity Analysis in Observational Research: introducing the E-Value. Ann Intern Med 2017;167(4):268-74. DOl PubMed

39. Statistics Canada. StatCan COVID-19: Data to Insights for a Better Canada. Ng E. COVID-19 deaths among immigrants: Evidence from the early months of the pandemic. Ottawa (ON): StatCan; 2021 (accessed 2021-06-11). https://www150. statcan.gc.ca/n1/pub/45-28-0001/2021001/article/00017eng.htm

40. Mustard CA, Etches J. Gender differences in socioeconomic inequality in mortality. J Epidemiol Community Health 2003;57(12):974-80. DOI PubMed 
41. Rosella LC, Calzavara A, Frank JW, Fitzpatrick T, Donnelly PD, Henry D. Narrowing mortality gap between men and women over two decades: a registry-based study in Ontario, Canada. BMJ Open 2016;6(11):e012564. DOI PubMed

42. Maclntyre S, Hunt K. Socio-economic position, gender and health: how do they interact? J Health Psychol 1997;2(3):315-34. DOl PubMed

43. Toronto Foundation. Toronto Fallout Report: Half a year in the life of COVID-19. Toronto (ON): Toronto Foundation; 2020 (accessed 2021-11-03). https://torontofoundation.ca/ wp-content/uploads/2020/11/Toronto-Fallout-Report-2020. pdf

44. Rose G. Sick individuals and sick populations. Int J Epidemiol 2001;30(3):427-32. DOl PubMed

45. Rose G, Khaw KT, Marmot M. Rose's Strategy of Preventive Medicine. USA: Oxford University Press; 2008. DOI
46. Statistics Canada. Table 1: Change in main place of work by level of education, Canada, March 22 to March 28, 2020. Ottawa (ON): StatCan; 2020 (accessed 2021-06-11). https://www150.statcan.gc.ca/n1/daily-quotidien/200417/ t001a-eng.htm

47. Marmot M, Allen J, Bell R, Bloomer E, Goldblatt P; Consortium for the European Review of Social Determinants of Health and the Health Divide. WHO European review of social determinants of health and the health divide. Lancet 2012;380(9846):1011-29. DOI PubMed

48. Whitehead M. The concepts and principles of equity and health. Health Promot Int 1991;6(3):217-28. DOl PubMed

49. Chagla Z, Ma H, Sander B, Baral SD, Mishra S. Characterizing the disproportionate burden of SARS-CoV-2 variants of concern among essential workers in the Greater Toronto Area, Canada. medRxiv 2021; 2021.03.22.21254127v2. https://www.medrxiv.org/content/10.1101/2021.03.22.2125 4127v2

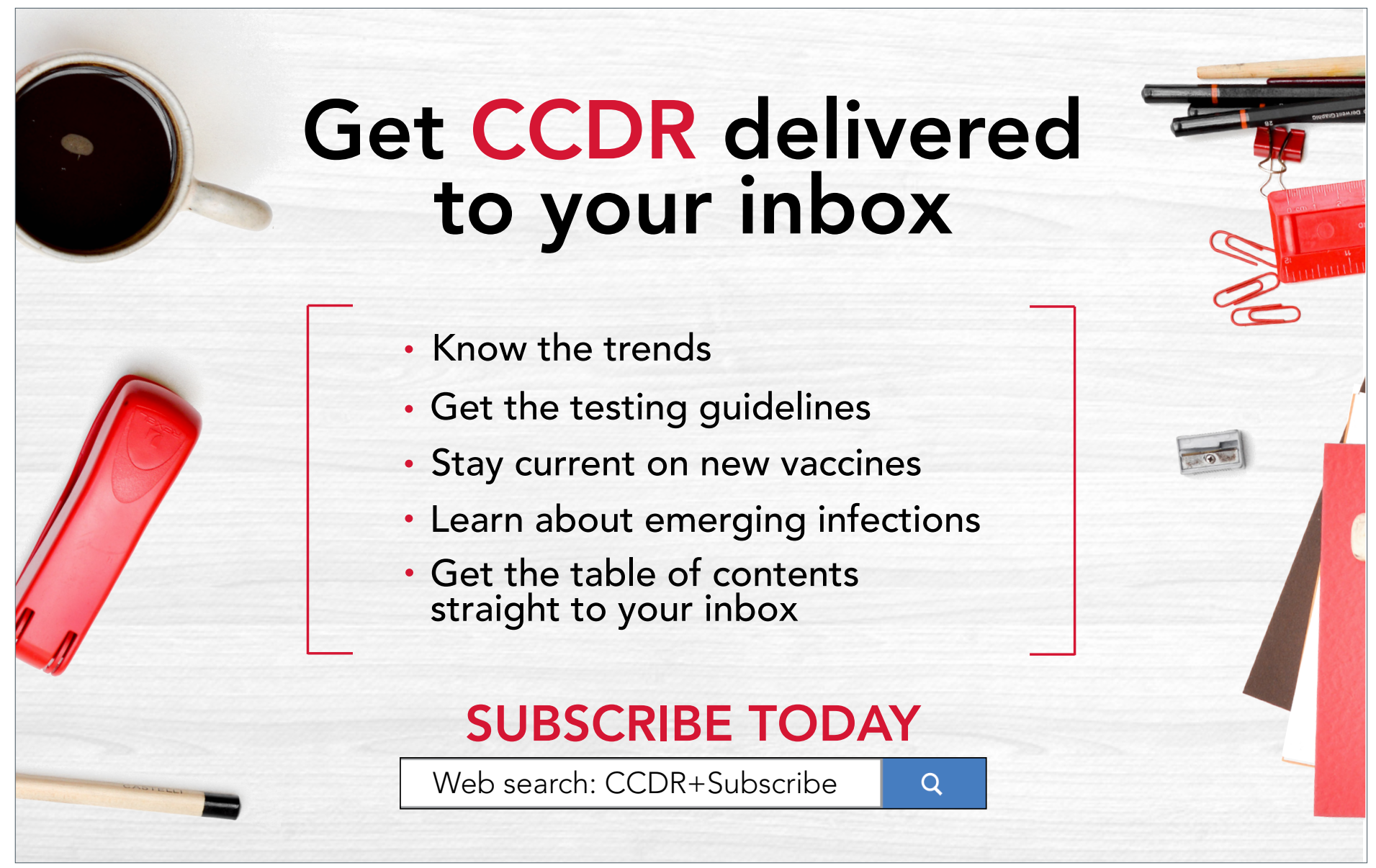

